\title{
CORRIGENDA
}

\section{Cereblon is a direct protein target for immunomodulatory and antiproliferative activities of lenalidomide and pomalidomide}

A Lopez-Girona, D Mendy, T Ito, K Miller, AK Gandhi, J Kang, S Karasawa, G Carmel, P Jackson, M Abbasian, A Mahmoudi, B Cathers, E Rychak, S Gaidarova, R Chen, PH Schafer, H Handa, TO Daniel, JF Evans and R Chopra

Leukemia (2012) 26, 2445; doi:10.1038/leu.2012.235

Correction to: Leukemia; doi:10.1038/leu.2012.119; advance online publication, 3 May 2012

Since the publication of this article, the authors have noticed an error in Figure $4 a$, specifically that the structures of the methylpomalidomide enantiomers were missing a carbonyl group.
The error has now been rectified, and the correct article (with the correct figure 4) appears in this issue. The html and online pdf versions have also been rectified, and now carry the correct paper.

The authors would like to apologise for any inconvenience this may have caused.

\section{Direct interaction of PU.1 with oncogenic transcription factors reduces its serine phosphorylation and promoter binding}

A Seshire, T Rößiger, M Frech, S Beez, H Hagemeyer and E Puccetti

Leukemia (2012) 26, 2445; doi:10.1038/leu.2012.170

Correction to: Leukemia (2012) 26, 1338-1347; doi:10.1038/ leu.2011.331

Since the publication of this article, the authors have noticed an error contained within panel $\mathbf{f}$ of Figure 1 . The correct figure is shown here.
The authors would like to apologize for any inconvenience this may have caused. 


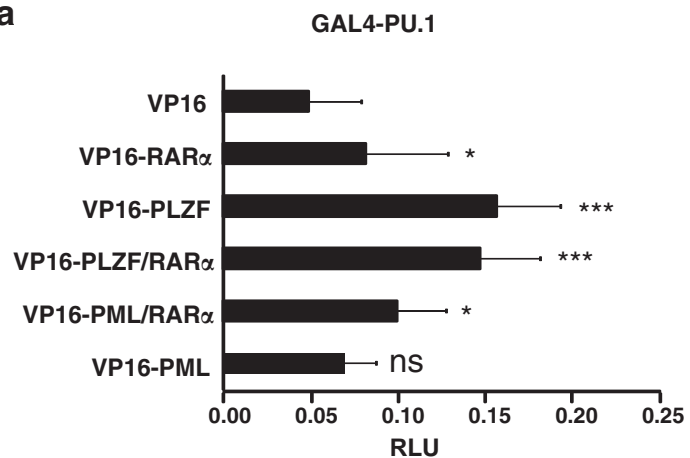

b

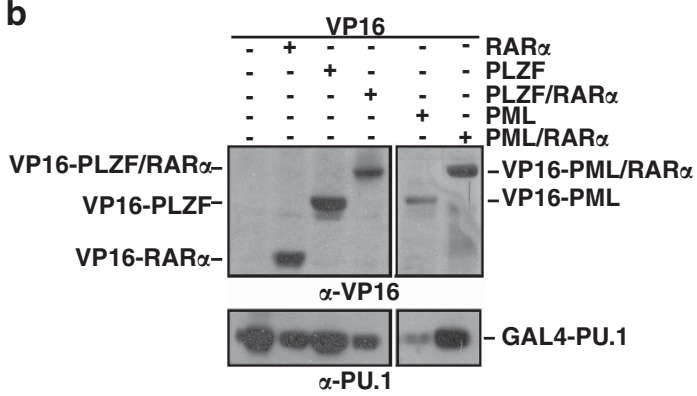

$\mathbf{C}$
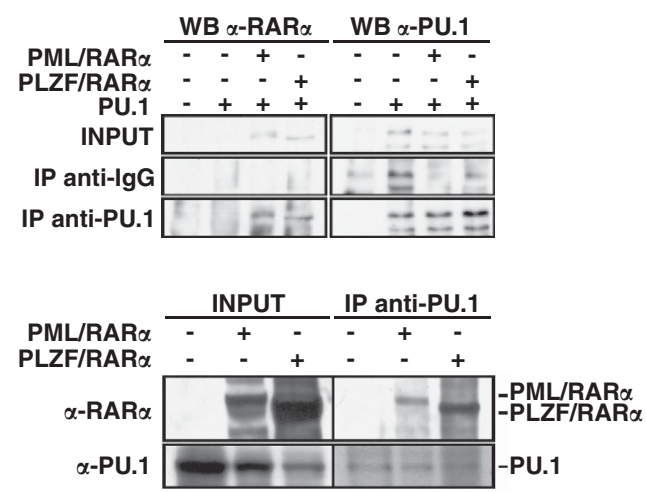

e

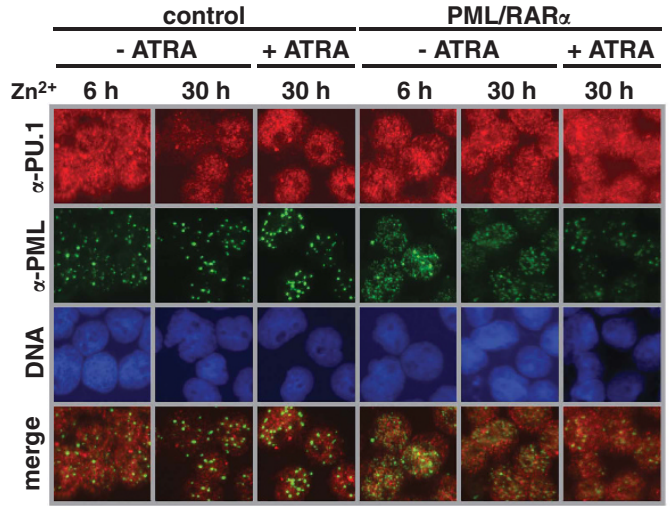

d

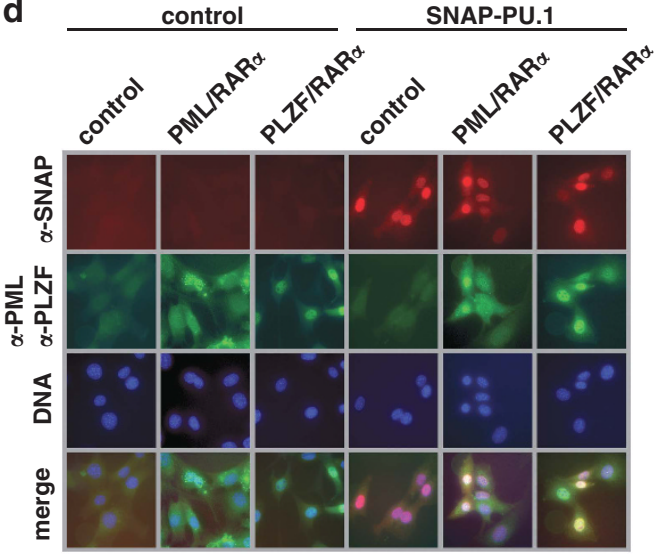

f

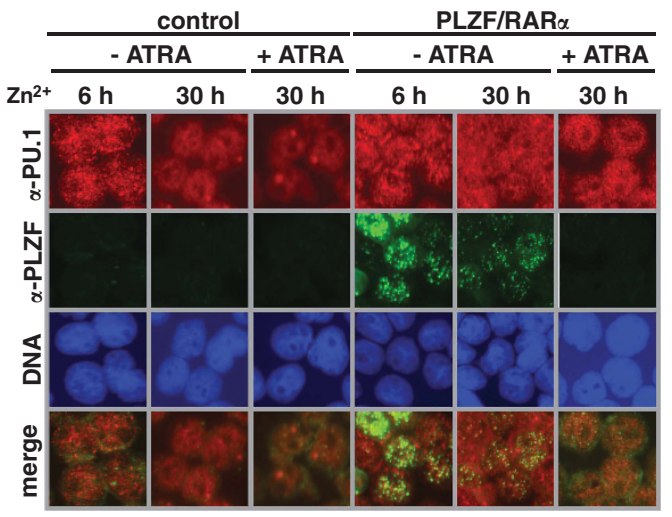

Figure 1. Interaction studies of PU.1 and the AML-associated fusion proteins. (a) 'Mammalian two-hybrid' (MTH) analysis. MTH assays were performed in 293 cells transfected with the PU.1 'bait' plasmid (GAL4-PU.1) and the respective 'prey' plasmid (VP16 empty control, VP16-RARa, VP16-PLZF, VP16-PLZF/RAR $\alpha$, VP16-PML and VP16-PML/RAR $\alpha$ ). The results are expressed as relative light units (RLU), representing the activation of the (GAL)4-luciferase reporter normalized to the internal renilla control. Data are presented as the mean \pm s.d. of three independent experiments, each performed in triplicates. ${ }^{*} P<0.05,{ }^{* * *} P<0.001$ and NS $=$ not significant represent the significance with respect to the VP16 control. Statistical analysis was performed by Student's $t$-test. (b) Western blot analysis of the expressed fusions. Proteins were separated by SDS-PAGE and transferred onto nitrocellulose membranes. The membranes were probed with anti-VP16 or anti-PU.1 antibodies as indicated. (c) (Upper panel) co-immunoprecipitation (IP) of Phoenix cells expressing X-RAR $\alpha$ and PU.1 as indicated. IP was performed with the anti-PU. 1 antibody and western blot analysis was performed using the indicated antibodies. Input, $5 \%$ of the protein amount used for the co-IP reaction. (Lower panel) IP was performed with the anti-PU.1 antibody under ChIP conditions, and western blot analysis was performed using the indicated antibodies. Control, mock-transfected U937 cells. Input, 25\% of the protein amount used for the co-IP reaction. (d-f) Influence of the expression of PML/RAR $\alpha$ and PLZF/RAR $\alpha$ on the localization of PU.1. Control, wild-type cells or cells transfected with empty plasmids. Cells were stained with Hoechst 33342 and the indicated antibodies. Anti-SNAP, polyclonal rabbit antibody conjugated to red fluorochrome (anti-SNAP). Anti-PU.1, polyclonal rabbit antibody conjugated to red fluorochrome (anti-PU.1). Anti-PML and anti-PLZF, monoclonal mouse antibodies conjugated to green fluorochrome (anti-PML and anti-PLZF). Co-localization images were obtained by electronic overlapping of the images (merge). Co-localization of the red and green fluorochromes yields a yellow color. (d) NIH-3T3 cells were transfected as indicated. (e, f) U937 cells harboring the indicated fusion protein or empty control. 